\title{
TRAUMA E PULSÃO DE MORTE EM FERENCZI*
}

Regina Herzog e Fernanda Pacheco-Ferreira

\author{
Regina Herzog \\ Psicanalista, \\ professora associada \\ do Programa de \\ Pós-Graduação em \\ Teoria Psicanalítica \\ da UFRJ; \\ pesquisadora de \\ produtividade em \\ pesquisa do $\mathrm{CNPq}$; \\ coordenadora do \\ Núcleo de Estudos \\ em Psicanálise \\ e Clínica da \\ Contemporanei- \\ dade (Nepecc/ \\ UFRJ). \\ Fernanda Pacheco- \\ Ferreira \\ Psicanalista, \\ pós-doutoranda \\ do Programa de \\ Pós-Graduação em \\ Teoria Psicanalítica \\ da UFRJ \\ (PNPD/Capes); \\ pesquisadora do \\ Núcleo de Estudos \\ em Psicanálise \\ e Clínica da \\ Contemporanei- \\ dade (Nepecc/ \\ UFRJ).
}

RESUMO: Pretende-se buscar na obra de Ferenczi (textos e notas publicadas em seu Diário) os indícios de seu distanciamento das orientações de Freud em relação à pulsão de morte. Com isso esperamos mostrar que com Ferenczi se inaugura uma clínica centrada nas relações precoces do Eu com seus objetos primários, abrindo caminho para repensar o papel do objeto na constituição psíquica. Para tanto, abordaremos seu conceito de introjeção, bem como suas reflexões acerca do trauma desestruturante.

Palavras-chave: Trauma, pulsão de morte, introjeção, Ferenczi.

ABSTRACT: Trauma and death drive in Ferenczi. In this article we intend to search in the work of Ferenczi (texts and notes published in his Journal) the evidence of his detachment from Freud's guidelines regarding the death drive. Thus we hope to show that with Ferenczi a clinic focused on the early relationships of the self with its primary objects is unveiled, paving the way for rethinking the role of the object in psychic constitution. Therefore, we discuss his concept of introjection as well as his considerations about the pathological trauma.

Keywords: Trauma, death drive, introjection, Ferenczi.

DOI - http://dx.doi.org/10.1590/S1516-14982015000200002

\footnotetext{
* Este artigo faz parte da pesquisa produzida pelas autoras no âmbito do projeto Prodoc/Capes (2010-2014), com o apoio institucional do
Programa de Pós-Graduação em Teoria Psicanalítica da Universidade do projeto Prodoc/Capes (2010-2014), com o apoio institucional do
Programa de Pós-Graduação em Teoria Psicanalítica da Universidade Federal do Rio de Janeiro. Parte das ideias aqui desenvolvidas também
são fruto da tese de doutorado de Fernanda Pacheco-Ferreira, sob Federal do Rio de Janeiro. Parte das ideias aqui desenvolvidas também
são fruto da tese de doutorado de Fernanda Pacheco-Ferreira, sob orientação de Octavio Souza, defendida na PUC-Rio, em 2008.
} 
0 conceito de pulsão de morte, apresentado em 1920, foi recebido pela comunidade analítica com muitas ressalvas. A grande maioria dos psicanalistas pós-freudianos não adota o conceito, ao menos tal como Freud inicialmente o concebeu, enquanto uma tendência inata e universal. Entretanto, as manifestações clínicas atribuídas à pulsão de morte nunca deixaram de intrigar os analistas, e muito da reflexão psicanalítica do século XXI remete às questões levantadas por Freud a partir de 1920 diante do encontro com uma dimensão que estaria além do princípio de prazer e além da representação.

Um dos primeiros analistas a abordar as manifestações da pulsão de morte na clínica, oferecendo, mesmo que de modo não explícito, uma alternativa à ideia original do conceito, foi Sándor Ferenczi, cuja influência para a psicanálise contemporânea é, hoje, incontestavelmente reconhecida. É nosso intuito sinalizar em que medida a perspectiva ferencziana aborda as manifestações da compulsão à repetição sem apelar para o conceito especulativo de pulsão de morte, o que acaba por impactar de maneira mais global o próprio edifício metapsicológico. Ferenczi abre, assim, espaço para se pensar questões que escapam ao paradigma da representação e dos operadores da castração e do recalque, ampliando, segundo nosso ponto de vista, o próprio campo de intervenção terapêutica.

A partir da virada de 1920, podemos localizar o germe das discussões que, décadas depois, provocariam verdadeiras cisões no campo psicanalítico. Como lembra Green (1990, p.21), Freud não se dedicava à questão do manejo da clínica desde 1914 e, quando retomou a questão em Análise terminável e interminável e Construções em análise, em 1937, só fez coro à decepção de sua entourage ao identificar na combinação da repetição com a destrutividade um obstáculo praticamente intransponível e incontornável para o processo analítico.

As mais novas descobertas de Freud (1920) causaram, portanto, grande mal-estar em relação às perspectivas terapêuticas, tendo a comunidade analítica reagido como se estivesse diante de uma possível sentença de morte da psicanálise. Isto porque para muitos analistas da época, mais do que para o próprio Freud, o sucesso da teoria estava intrinsecamente ligado à terapêutica. Assim, a partir dos remanejamentos articulados em 1920, questões de ordem mais técnica ocuparam os analistas que se perguntavam como ultrapassar a compulsão à repetição e dar continuidade ao trabalho analítico. Na busca de respostas, os discípulos de Freud, sobretudo Ferenczi, deslocaram o predomínio do ponto de vista teórico para uma discussão eminentemente clínica.

A atualidade do pensamento de Ferenczi vai atender à necessidade de se refletir sobre esta sentença de morte que parece se perpetuar nos dias de hoje na crítica contundente em relação ao método, à intervenção terapêutica e ao arcabouço teórico da psicanálise. Assim é que nos deparamos com a denúncia de que o arcabouço teórico da psicanálise, bem como seu dispositivo clínico, 
estaria ultrapassado, pois suas ferramentas não seriam mais eficazes para dar conta das transformações no modo de se pensar o sujeito na contemporaneidade. Ou seja, hoje não estamos mais diante de perturbações psíquicas referidas ao modelo do recalque.

Pretendemos, aqui, buscar no pensamento de Ferenczi, em textos e notas publicadas em seu Diário, os indícios de seu distanciamento das orientações de Freud em relação à pulsão de morte. Com isso esperamos mostrar que com Ferenczi se inaugura uma clínica centrada nas relações precoces do Eu com seus objetos primários, abrindo caminho para repensar o papel do objeto na constituição psíquica. Porém, antes de nos determos propriamente na questão da pulsão de morte, é preciso abordar, ainda que de modo breve, o conceito de introjeção, pois foi por meio desta noção que Ferenczi pôde concentrar-se sobre a experiência de ser e sua articulação com o universo libidinal não redutível à experiência pulsional (VERZTMAN \& PACHECO-FERREIRA, 2008).

Introduzida em 1909, e reorganizada em 1912, a introjeção está na origem da relação com qualquer objeto, no sentido da apropriação e transformação dos objetos interessantes do mundo externo em partes do eu. Para Ferenczi, a introjeção se define como a "fusão desses objetos com o nosso ego" e, nesse sentido, o "mecanismo dinâmico de todo amor objetal e de toda transferência para um objeto é uma extensão do ego, uma introjeção" (FERENCZI, 1912, p.181-2). Nesta medida, a relação objetal, tal como foi descrita por Freud, se daria em um segundo momento, posterior à introjeção. A este propósito, Pinheiro (1995) considera que podemos encontrar muitas similitudes entre esta noção e o conceito de narcisismo, a ser introduzido por Freud dois anos depois. Para esta autora, a introjeção em Ferenczi é a própria condição de possibilidade do funcionamento do aparelho psíquico e da "inclusão na esfera psíquica do diferencial prazer/desprazer (responsável pela instauração da ordem psíquica sob a regência do princípio de prazer)" (PINHEIRO, 1995, p.46).

Acompanhando as concepções posteriores de Ferenczi acerca do papel do meio ambiente, percebe-se que essa estruturação narcísica não está dada de saída: o meio precisa estar disponível e ser maleável o suficiente para que os obstáculos que naturalmente se apresentarão não entravem o processo introjetivo. Em um primeiro momento, Ferenczi considerava a introjeção e, consequentemente, a transferência e o deslocamento, como tendências inerentes ao funcionamento neurótico. Contudo, a clínica lhe mostrará que existem introjeções possíveis e outras que não o são; isso ficará mais claro quando abordarmos mais adiante seu desenvolvimento sobre o trauma. ${ }^{1}$

\footnotetext{
${ }^{1}$ É importante esclarecer que, para Ferenczi, existem traumas estruturantes e desestruturantes. Neste artigo trataremos exclusivamente do trauma desestruturante.
} 
Para finalizar essa breve incursão pelo conceito de introjeção, é interessante destacar que esta concepção prescinde de um ponto de vista dualista, sempre privilegiado por Freud. Para Ferenczi (1909), no início da vida o bebê tem uma experiência monista do mundo e apenas mais tarde "aprenderá a 'malícia das coisas", o monismo se converteria, assim, em dualismo como efeito do contato com o ambiente. O monismo da experiência do bebê é fundamental para a ideia de introjeção, já que não implica na necessidade de um prévio desligamento energético para seu funcionamento. Mais tarde, em 1926, esta relação entre introjeção e universo monista da criança fica mais clara, conforme a citação abaixo:

"Recorrendo à terminologia psicanalítica, designei a primeira fase, aquela em que só existe o ego e em que este se apropria de todo o universo da experiência, como o período de introjeção; a segunda fase, aquela em que a onipotência é atribuída a potências exteriores, como o período de projeção; quanto ao último estágio de desenvolvimento, pude concebê-lo como o período em que os dois mecanismos são utilizados em partes iguais e compensam-se mutuamente.” (FERENCZI, 1926, p.399)

O conceito de introjeção é um indício de que Ferenczi, a despeito de considerar que estava em completa sintonia com Freud, já nessa época apresentava uma perspectiva diferente em relação à teoria pulsional. Pinheiro (1995) observa, por exemplo, que o processo introjetivo é concebido como uma produção de sentido sem vínculo com a ordem somática. Para a autora, “a introjeção é ao mesmo tempo uma qualidade da pulsão (cujo processo é fiador do movimento contínuo de investimento num universo concebido desde o início como intersubjetivo), e a responsável pelo advento do sexual no aparato psíquico (PINHEIRO, 1995, p.47).

Mesmo quando os dois, Freud e Ferenczi, trabalhavam em projetos em conjunto, a diferença de enfoque já podia ser notada. Sabe-se por sua correspondência que ambos pretendiam empenhar-se em um projeto sobre Lamarck ${ }^{2}$, ao qual Freud acaba por renunciar em $1917^{3}$. Ferenczi, no entanto, parece ter dado

2 “(...) o psicanalista sente-se mais atraído pelo modo de pensar de Lamarck, mais centrado na psicologia na medida em que reconhece igualmente um papel para as tendências e os movimentos pulsionais na filogenia, ao passo que o grande naturalista britânico [Darwin] coloca tudo na dependência da mutação, logo, em última análise, do acaso. A concepção darwiniana também pouco explica essa repetição das formas e dos modos de funcionamento antigos nos novos produtos da evolução, repetição que se reencontra por toda a parte na natureza. Com toda probabilidade, essa concepção rejeitaria a noção de regressão, que não pode ser dispensada pela psicanálise" (FERENCZI, 1924, p.292).

${ }^{3}$ Em 27 de dezembro de 1917, Freud escreve a Ferenczi: "Mas eu não consigo me decidir pelo [trabalho sobre] Lamarck. É talvez como para os nobres poloneses no momento de pagar: "nenhum dos dois aceitando que o outro pagasse por ele, nenhum dos dois pagou'" (BRABANT et al., 1996, p.283). Cabe lembrar que um manuscrito, sobre Lamarck, foi en- 
prosseguimento à empreitada: Thalassa é o resultado de suas trocas sobre a relação entre a ontogênese e a filogênese na transmissão da memória da espécie. Embora Ferenczi não se oponha às hipóteses de Freud em Além do princípio do prazer (1920), é justamente neste ensaio de 1924 que se pode perceber um desacordo em relação ao postulado freudiano da hegemonia da pulsão de morte no psiquismo. A este respeito, Avello (2013) considera que desde 1924 Ferenczi já não compartilhava da noção de primazia da pulsão de morte, preferindo à la Nietzsche, uma oscilação entre pulsões de vida e de morte. Segundo Avello, Ferenczi pensa em variantes da pulsão de vida que adquirem sua estrutura definitiva no laço com os outros e não em pulsões distintas.

“(...) deveríamos abandonar definitivamente o problema do começo e do fim da vida e imaginar todo o universo orgânico e inorgânico como uma oscilação perpétua entre pulsões de vida e pulsões de morte, em que tanto a vida quanto a morte jamais conseguiria estabelecer sua hegemonia." (FERENCZI, 1924, p.325)

E mesmo antes de Thalassa, em 1913, quando Ferenczi faz uma breve menção a uma tendência à inércia em seu artigo sobre o desenvolvimento do princípio de realidade e seus estados (o primeiro artigo escrito sobre o desenvolvimento do Eu, dirá Balint ${ }^{4}$ ), percebe-se uma preocupação acentuada com o papel do meio ambiente. Nesta nota, ele afirma que a tendência para a inércia ou para a regressão dominaria a vida orgânica e que "a tendência para a evolução, para a adaptação, etc., dependeria, pelo contrário, unicamente de estímulos externos" (p.52, grifos nossos). Ainda neste artigo Ferenczi afirma que a experiência de onipotência do feto, decorrente de "ter tudo o que se quer e de não ter mais nada a desejar", não é forçosamente abandonada caso o meio cumpra uma função que ele denomina conciliadora. "Se a criança é tratada com amor, não será obrigada, mesmo nesse estágio de sua existência, a abandonar sua ilusão de onipotência”. Nota-se que Ferenczi concede, já nessa época, um papel importante ao meio ambiente, fazendo com que a tônica de suas reflexões recaia sobre a relação do sujeito com o objeto.

Ferenczi não rejeita de modo explícito o conceito de pulsão de morte, diferentemente de Balint, seu discípulo direto, e de Winnicott, seu herdeiro indireto, que o aboliram de sua teoria e prática. A nosso ver, contudo, o uso do conceito de pulsão de morte parece sofrer uma modificação significativa ao longo de seus textos. Assim, quando Freud introduz a nova dualidade pulsional entre vida e morte, Ferenczi parece recuar não apenas diante da hegemonia da última

contrado nos arquivos de Freud e publicado no Brasil em 1987, com o título "Neuroses de transferência: uma síntese".

${ }^{4}$ Cf. Balint, 1992, p.XI. 
em relação à primeira, como queria Freud, mas, sobretudo, diante da hipótese constitucional da pulsão de morte. Através das notas de seu Diário, publicado postumamente, observa-se que pouco a pouco ele chega a eliminar a pulsão de morte da dinâmica psíquica: só existiriam pulsões de vida. ${ }^{5}$

Em O problema da afirmação do desprazer, de 1926, Ferenczi retoma as ideias introduzidas no trabalho sobre o desenvolvimento do princípio de realidade e seus estados, à luz das descobertas de Freud sobre a negação. Neste artigo, como já salientado, Ferenczi afirma que a distinção entre as coisas boas e más, entre o ego e o meio ambiente, o interior e o exterior, só se estabeleceria mais tarde; estranho e hostil seriam idênticos nessa primeira etapa. Assim, quando uma criança que sempre foi apaziguada no momento certo sofre o desprazer da fome e da sede, ocorreria uma espécie de desintrincamento pulsional na vida psíquica, manifestado por descarga motora descoordenada e choro. O próximo reencontro com o seio será marcado por esse desprazer, modificando a relação.

“(...) o seio materno passa agora a ser um objeto de amor e de ódio; de ódio porque se foi obrigado a passar sem ele durante um certo tempo, de amor porque depois dessa privação ele lhe propiciou uma satisfação ainda mais intensa; mas, de toda maneira, torna-se a matéria de uma representação de objeto, ainda muito vaga, sem dúvida." (FERENCZI, 1926, p.397)

A percepção do objeto e, concomitantemente, a gênese do Eu estão, portanto, em relação direta com o desintrincamento pulsional face ao objeto primordial. Para explicitar como se dá tal relação, cabe acompanhar a própria argumentação de Ferenczi que se configura de grande relevância no bojo de seu pensamento.

“Certos organismos primitivos parecem ter permanecido no estágio narcísico; aguardam passivamente a satisfação de seus desejos e se esta lhes for constantemente recusada, eles morrem - pura e simplesmente; encontram-se ainda tão próximos do ponto de emergência para fora do inorgânico que sua pulsão de destruição tem muito menos caminho a percorrer para a ele retornar e mostra-se, portanto, muito mais eficaz. Num estágio mais evoluído, o organismo é capaz de rejeitar partes de si mesmo que constituem para ele fontes de desprazer e de salvar assim sua própria vida (autotomia ${ }^{6}$ ); essa espécie de 'sequestro' pareceu-me ser outrora o protótipo

\footnotetext{
5 “Nothing but life instincts. Death-instinct, a mistake (Pessimistic)", in Ferenczi apud Dupont, 1998.

${ }^{6}$ A autotomia é um modo de reação por meio do qual o animal desprende de seu corpo, ou seja, 'deixa cair', os órgãos que estiverem submetidos a uma irritação excessiva. Segundo Ferenczi, este seria o modelo biológico do recalcamento: a fuga psíquica diante dos sentimentos demasiado intensos de desprazer. Acreditamos, contudo, que a imagem da autotomia
} 
fisiológico do processo de recalcamento. É preciso esperar uma outra etapa do desenvolvimento para ver surgir a faculdade de adaptação à realidade, espécie de reconhecimento orgânico do mundo exterior que é manifesto no modo de vida dos seres que vivem em simbiose, mas igualmente em todo ato de adaptação." (FERENCZI, 1926, p.400)

Nesta longa passagem, duas ideias necessitam menção: a primeira é a afirmação de que o frágil organismo sucumbe ao estado inorgânico do qual emergiu recentemente, caso o ambiente não satisfaça suas necessidades básicas. A segunda diz respeito ao mecanismo de defesa, passível de se desenvolver num momento posterior, que consiste em expelir, cindir partes de si mesmo, como estratégia de sobrevivência diante de uma ameaça de perigo iminente. Ambas as afirmações estão interligadas e serão amplamente desenvolvidas nos trabalhos subsequentes de Ferenczi. A primeira está relacionada à sua compreensão da pulsão de morte e a segunda se insere em suas reflexões sobre o trauma.

Propomos adotar essas duas linhas de desenvolvimento em conjunto, a da pulsão de morte e a do trauma desestruturante, para compreender a contribuição de Ferenczi à teoria das pulsões e mostrar como sua posição abre caminho para a teoria das relações de objeto. Assim, no artigo intitulado "A criança mal acolhida e sua pulsão de morte” (1929), Ferenczi dá seguimento à reflexão sobre a força da pulsão de destruição no início da vida, questionando a concepção freudiana. Para Ferenczi, não fazia sentido pensar um funcionamento autônomo e inexorável dos fenômenos vitais, como um emaranhado de manifestações de duas pulsões básicas, a de vida e a de morte, não subordinado às relações intersubjetivas que constituem a história de vida de cada um. Para tanto, começa pela observação de pacientes com tendências suicidas e, mais especificamente, da análise retrospectiva de dois casos de espasmo da glote infantil, interpretando-os como tentativas de suicídio por autoestrangulamento. Para ele, crianças mal acolhidas, ou seja, recebidas com rudeza e sem carinho, captam de forma consciente e inconsciente os sinais de aversão do meio e sua vontade de viver se quebra. "Morrem facilmente e de bom grado", diz ele, mas, se sobrevivem, são acompanhadas por um desprazer e pessimismo em relação à vida. Ferenczi notou em muitos desses casos manifestações de impotência sexual, disposição para resfriados e até mesmo uma queda noturna de temperatura muito acentuada e sem explicação orgânica. Tais casos, nos quais o gosto pela vida é tão precocemente perdido, seriam semelhantes aos daqueles pacientes que, segundo Freud, "sofrem de uma fraqueza congênita de sua capacidade para viver” com a diferença, porém, de que,

não diz respeito diretamente ao recalque, ela estaria antes na origem do conceito de clivagem (Cf. Câmara et al., trabalho apresentado no International Sándor Ferenczi Congress, Toronto, maio de 2015). 
para Ferenczi, este suposto “caráter congênito da tendência mórbida é simulado, em virtude da precocidade do trauma” (FERENCZI, 1929, p.50).

“(...) no início da vida, intra e extrauterina, os órgãos e suas funções desenvolvem-se com uma abundância e uma rapidez surpreendentes — mas só em condições particularmente favoráveis de proteção do embrião e da criança. (...) A 'força vital' que resiste às dificuldades da vida não é, portanto, muito forte no nascimento; segundo parece, ela só se reforça após a imunização progressiva contra os atentados físicos e psíquicos, por meio de um tratamento e uma educação conduzidos com tato." (FERENCZI, 1929 , p.50, grifos nossos)

De acordo com Ferenczi, o pequeno sujeito que acaba de vir ao mundo encontra-se muito próximo do "não-ser individual" e deslizar novamente para tal estado poderia, no caso da ausência da "imunização" do meio, acontecer de modo muito mais fácil do que com um adulto. O ponto chave aqui é o termo “imunização” que mostra como Ferenczi se distancia de uma hipótese constitucional para valorizar o ‘tato’ do meio ambiente. É em 1928, no artigo “Elasticidade da técnica psicanalítica”, que o conceito de tato é mais bem trabalhado. "O tato é a faculdade de 'sentir com' (Einfühlung)” (FERENCZI, 1928, p.27). Essa noção não tem um caráter místico ou puramente intuitivo, trata-se apenas de uma capacidade psicológica, empática, de se colocar no mesmo diapasão da criança (ou do paciente) e sentir com ele todos os seus caprichos e humores.

No tratamento de tais casos, o analista permite ao paciente "desfrutar pela primeira vez a irresponsabilidade da infância, o que equivale a introduzir impulsos positivos de vida e razões para se continuar existindo" (FERENCZI, 1929, p.51). Daí tira-se uma primeira conclusão: a pulsão de vida, enquanto tendência erótica e força vital, embora parte integrante do ser humano, só cumpre sua função caso o ambiente favoreça sua dinamização. Pode-se pensar que o mesmo se aplica à pulsão de morte, a falha na imunização corresponderia a um recrudescimento da tendência ao inorgânico. Ambas as tendências dependeriam das primeiras relações do indivíduo com o meio circundante e não estariam ligadas à constituição. Suas palavras a este respeito são eloquentes: “A criança recém-nascida utiliza toda a sua libido para o seu próprio crescimento, e é necessário até dar-lhe libido para que possa crescer normalmente. (...) Os bebês não amam, é preciso que sejam amados” (FERENCZI, 1932, p.236).

O verdadeiro distanciamento de Freud se deu com o desenvolvimento de sua teoria do trauma. No final da vida, a teoria do trauma e a consequente revalorização do objeto, levaram Ferenczi a questionar o ponto de vista econômico tal qual pensado por Freud, o equilíbrio energético entre as pulsões de vida e de morte, acabando por conduzi-lo a uma concepção nova do psiquismo, que impli- 
caria a ideia de um monismo energético. Com isso, Ferenczi não estaria apenas chamando a atenção para um caso particular que escapa à psicanálise clássica. Ao reavaliar o fator traumático de casos graves, ele também está reformulando, à sua maneira, a compreensão global do aparelho psíquico. Pode-se dizer que uma soma de fatores, tais como seu estado crítico de saúde, a reavaliação de sua própria análise com Freud - que não teria trabalhado a transferência negativa durante o tratamento - e o excesso de preocupação com o manejo clínico, impediram-no de formalizar suas intuições de modo explícito no âmbito teórico.

Além disso, sabe-se que estas ideias desenvolvidas no final da vida não foram bem aceitas por Freud que, chocado, pediu inclusive a não publicação do artigo "Confusão de língua entre os adultos e a criança”, apresentado no congresso de Wiesbaden, em 1932. De fato, Freud mostrou-se profundamente decepcionado com o amigo, colega e discípulo, pedindo-lhe que reconsiderasse suas posições e mesmo que evitasse editar artigos por certo tempo. ${ }^{7}$ Neste texto de 1932, Ferenczi dá especial relevo à questão do trauma, indo contra "explicações apressadas, invocando a predisposição e a constituição” (FERENCZI, 1933, p.97).

\begin{abstract}
“(...) nunca será demais insistir sobre a importância do traumatismo e, em especial, do traumatismo sexual como fator patogênico. (...) A objeção, a saber, que se trataria de fantasias da própria criança, ou seja, mentiras histéricas, perde lamentavelmente sua força, em consequência do número considerável de pacientes, em análise, que confessam ter mantido relações sexuais com crianças.” (FERENCZI, 1933, p.101)
\end{abstract}

Ferenczi via no trauma desestruturante um fator exógeno, modificando o psiquismo. Para ele, a cena traumática é, na verdade, uma confusão de línguas, ou seja, refere-se à má compreensão por parte do adulto de manifestações eróticas da criança, tomando-as como análogas às manifestações da sexualidade adulta; ou seja, enquanto as primeiras permanecem sempre no nível da ternura, as manifestações adultas encontram-se no nível genital, da paixão.

A interpretação confusa desses dois níveis eróticos por parte do adulto provoca a confusão na criança, em especial quando o adulto, culpado, se retira e desmente o ocorrido. Para Ferenczi, essa confusão é traumática e patológica porque põe em risco o projeto identificatório do sujeito. Ao confundir a ternura da criança com o erotismo genital, o adulto falha como suporte mediador entre a criança e seu mundo, traindo sua confiança. Podemos dizer que, neste processo, a própria

\footnotetext{
7 “Não acredito mais que você se corrija, como eu me corrigi uma geração mais cedo... Nos últimos dois anos, você se distanciou sistematicamente de mim... Acredito estar objetivamente em condições de lhe mostrar o erro teórico em sua construção, mas de que adianta? Estou convencido de que você se tornou inacessível a qualquer reconsideração" (FREUD apud DUPONT, 1985, p.17).
} 
criança enquanto sujeito é desacreditada. Ou seja, o trauma desestruturante se configura na falha das instâncias de mediação entre os dois jogos de linguagem. Para Ferenczi, como observa Green, não se tratava apenas de sedução, mas de violação (psíquica) pelo excesso de demanda ou privação de amor parental. O total desconhecimento das necessidades da criança provocaria, assim, "paralisia psíquica por sideração devida ao desespero” (GREEN, 1990, p.28). A teoria do trauma passa de considerações predominantemente quantitativas a considerações qualitativas, subordinadas às relações intersubjetivas ${ }^{8}$ em questão.

O efeito do trauma será análogo a um golpe devastador no psiquismo. A culpa experimentada pelo adulto é assumida pela criança, pela via de um mecanismo que Ferenczi denominou identificação ao agressor, na busca de preservar o adulto enquanto modelo identificatório. O desmentido engendra, portanto, um tipo particular de submissão, no qual o adulto desaparece da realidade externa e ocupa todo o espaço interno da criança, conturbando a constituição de um universo subjetivo próprio. Podemos compreender este mecanismo como uma última tentativa de introjeção, no sentido de simbolizar o ocorrido, já que o desmentido anula qualquer vestígio do fato, exceto a culpa do adulto que parasita a criança. O cerne deste mecanismo seria adquirir segurança e, ao mesmo tempo, conservar a esperança de algum controle onipotente. Trata-se de um mecanismo de sobrevivência, portanto, de uma saída que o sujeito encontra para lidar com algo que não pode ser apropriado subjetivamente, introjetado. Quando o processo de introjeção falha, o mecanismo da incorporação (Cf. Abram \& Torok, 1995) tem lugar. E é justamente o que não pôde ser introjetado que assume um efeito mortífero no psiquismo. Nas palavras de Ferenczi:

“As crianças sentem-se física e moralmente sem defesa, sua personalidade é ainda frágil demais para poder protestar (...). Mas esse medo, quando atinge seu ponto culminante, obriga-as a submeter-se automaticamente à vontade do agressor. Por identificação, digamos, por introjeção do agressor, este desaparece enquanto realidade exterior, e torna-se intrapsíquico (...). Seja como for, a agressão deixa de existir

\footnotetext{
${ }^{8}$ Em 1920, como se sabe, Freud faz os últimos acréscimos à sua teoria do trauma com a ideia de uma ruptura do sistema para-excitação por excesso quantitativo de excitação, abatendo o princípio de prazer e ameaçando o aparelho psíquico de implosão. Com o rompimento do escudo protetor contra os estímulos e a saída de cena do princípio de prazer, a compulsão à repetição se instala na busca de neutralizar a ação devastadora do excesso de energia através da ligação com representações. Ferenczi vai traduzir, em termos intersubjetivos, a ideia de uma crise da capacidade de ligação, exposta por Freud, em termos intrapsíquicos, em Além do princípio de prazer. Seria injusto dizer que Freud não leva em conta o ambiente, ou o papel real dos primeiros objetos para a constituição da subjetividade e para a etiologia patológica, o que se quer ressaltar é que suas formulações acabam sempre privilegiando uma perspectiva que foca as mudanças internas ao aparelho psíquico.
} 
enquanto realidade exterior e estereotipada, e, no decorrer do transe traumático, a criança consegue manter a situação de ternura anterior.” (FERENCZI, 1933, p.102)

O acontecimento traumático fica clivado, inacessível à memória, ou poderíamos dizer, inacessível a uma "memória com lembranças", visto que suas marcas sobrevivem como impressões sensíveis, isto é, de ordem sensório-motora. Nessas condições, o vivido subjetivo conserva um caráter atual, conturbando a inscrição e o reordenamento temporal. Estaríamos, então, diante de marcas memoriais não revividas por recordações, mas, através do material perceptivo (PACHECO-FERREIRA, MELLO \& HERZOG, 2013). O conceito de clivagem e a imagem da autotomia, que pode ser considerada como sua precursora, são, portanto, respostas radicais a uma situação insuportável na relação com o ambiente. Neste contexto, uma autodestruição antecipa uma destruição exterior, como estratégia de sobrevivência, inaugurando uma nova tópica que não obedece à lógica do recalque (Cf. Câmara et. al., 2015). É interessante notar que o conceito de pulsão de morte não participa dessa montagem.

Nessa nova tópica, o trauma ganha a cena, referido como não representável, ${ }^{9}$ ao que não pôde ser inscrito e, portanto, impedido de recalcamento, pois, através do desmentido, o adulto força a criança à não simbolização. Ferenczi retrata um quadro no qual a imposição do sentido pelo agressor implica uma asfixia da vida psíquica, provocando um empobrecimento do Eu. Ademais, cabe ressaltar que o trauma por ele descrito ultrapassa a ideia de uma mera imposição sexual excessiva, prematura e violenta; ele concerne fundamentalmente à qualidade da resposta dos objetos primordiais diante de uma situação devastadora para o sujeito. Nunca é demais insistir sobre o fato de que a parte clivada sobreviveria em segredo, privada da possibilidade de representação em um modo neurótico, ou seja, simbólico. Em seu diário clínico, o autor afirma que essa clivagem provoca "um estado de mimetismo que, tal como um reflexo condicionado, incita apenas a repetições” (FERENCZI, 1932, p.259). Para Ferenczi, os adultos forçam na criança a entrada de seus conteúdos psíquicos de caráter desagradável, "esses estranhos transplantes clivados vegetam ao longo da vida na outra pessoa" (FERENCZI, 1932, p.118). Tal processo lançaria a criança em uma maturidade precoce e não estruturante. Assim, Ferenczi chega a uma constituição totalmente nova do psiquismo infantil e do campo clínico, abrindo caminho para o pensamento de um autor como Winnicott, por exemplo.

\footnotetext{
${ }^{9}$ Embora consideremos essa nomeação por demais problemática, visto que falar de irrepresentável, não representacional ou pré-representacional parece indicar uma subordinação inexorável ao que é do registro do representacional, não será possível abordar tal questão neste artigo.
} 
Ferenczi, mais do que nenhum outro analista na época, soube reconhecer os efeitos mortíferos da pulsão de morte sublinhados por Freud, mas relutou em considerá-los uma tendência universal ligada à constituição. A causa era exógena, tais efeitos deveriam ser atribuídos ao conflito com o outro, à ausência de tato do meio ambiente. A este propósito, Green (2007) afirma:

"É significativo que com Ferenczi se abra uma alternativa à teoria pulsional, onde se pode antecipar, em germe, uma teoria relacional que só se ampliará. A dimensão intersubjetiva prend le pas sobre o intrapsíquico. As mudanças do intrapsíquico são sempre consequência de efeitos intersubjetivos." (GREEN, 2007, p.95)

Como já foi salientado, Ferenczi fazia parte dos analistas que reagiram em contra-ataque ao pessimismo terapêutico que passou a dominar cada vez mais a psicanálise a partir da virada de 1920. Foi ele, em realidade, seu maior combatente, sendo a preocupação com a clínica e com os resultados terapêuticos um tema onipresente em seus escritos. A preocupação do analista húngaro com a cura é realçada por Granoff (1998) que afirma: “Seu desejo de curar condicionou sua experiência clínica. Sua prática clínica levou-o a pesquisas técnicas. Sua teoria é a justificação delas" (p.146). Portanto, na medida em que Ferenczi ia desenvolvendo suas conhecidas inovações técnicas, munido do furor sanandi que lhe era peculiar, sua teorização também se modificava, distanciando-se da de Freud. Bonomi (2003) considera que Ferenczi mesmo sem se dar conta, modifica de modo substancial a metapsicologia freudiana: "segundo Freud, o princípio do prazer procurava um equilíbrio no seio do aparelho psíquico, ao passo que Ferenczi interessava-se principalmente pelo equilíbrio entre o indivíduo e seu meio cambiante" (p.54).

Retomamos com isso, nossa aposta na atualidade do pensamento de Ferenczi. Diante, hoje, de modalidades de padecimentos psíquicos que remetem a dificuldades no próprio processo de constituição narcísica, as questões levantadas por Ferenczi vão servir tanto para se repensar a metapsicologia quanto vão fornecer recursos técnicos a serem utilizados na intervenção terapêutica. Em um momento no qual as duas regras básicas do dispositivo clínico clássico parecem ter caído em desuso dado que a associação livre e a atenção flutuante pressupõem uma narrativa pautada no conflito entre o desejo e a proibição, ou seja, no modelo do recalque, a necessidade de se revisitar tanto a teoria quanto a clínica em busca de ferramentas para lidar com outras formas de organização psíquica se mostra premente.

Parafraseando João Cabral de Melo Neto quando se refere à poesia: nestas modalidades não se trata de 'falar sobre' mas de 'se dar a ver'. Nestes termos, Ferenczi é, sem dúvida, um forte aliado. 


\section{REFERÊNCIAS}

ABRAHAM, N. e TOROK, M. (1995) A casca e o núcleo. São Paulo: Escuta. AVELLO. J. J. (2013) L’île de rêves de Sándor Ferenczi. Paris: Campagne Première. BALINT, M. (s/d) Prefácio do doutor Balint. In: FERENCZI, S. Obras completas, Psicanálise II. São Paulo: Martins Fontes, 1992, p.IX-XII.

BONOMI, C. (2003) Trauma et la fonction symbolique de la psyché, Le Coq-héron 2003/3 (n.174), p.50-56. DOI 10.3917/cohe.174.0050.

BRABANT, E. et al. (ed) (1996) Correspondance Sigmund Freud - Sándor Ferenczi (1914-1919). Paris: Calmann-Lévy.

CÂMARA, L. et al. (2015) Traumatisme et utraquisme : les fondements théoriques du concept de clivage. Trabalho apresentado no International Sándor Ferenczi Congress, Toronto, may 2015.

DUPONT, J. (1990) Prefácio, in FERENCZI, S. Diário clínico. São Paulo: Martins Fontes, p.11-27.

(1998) Les notes brèves de Sàndor Ferenczi, in Le Coq-Héron, Ferenczi à Madrid: pulsion de mort, identification à l'agresseur, transfert et contra-transfert, n.149, p.69-83.

FREUD, S. (1996) Obras psicológicas de Sigmund Freud. Rio de Janeiro: Imago.

(1920) “Além do princípio de prazer”, v.XVIII, p.13-75.

(1937) “Análise terminável e interminável”, v.XXIII, p.231-270.

(1937b) “Construções em análise”v.XXIII, p.275-287.

FERENCZI, Sándor. (várias edições) Sándor Ferenczi: Obras completas,. São Paulo: Martins Fontes.

(1909/1991) “Transferência e introjeção”, Psicanálise I, p.77-108.

(1912/1991) "O conceito de introjeção”, Psicanálise I, p.181-183.

(1913/1992) "O desenvolvimento do sentido de realidade e seus estágios”, Psicanálise II, p.39-54.

(1924/1993) “Thalassa, ensaio sobre a teoria da genitalidade”, Psicanálise III, p.255-326.

(1926/1993) “O problema da afirmação do desprazer”, Psicanálise III, p.393-404.

(1928/1992) “Elasticidade da técnica psicanalítica', Psicanálise IV, p.25-36.

(1929/1992) “A criança mal acolhida e sua pulsão de morte”, Psicanálise IV, p.47-52.

(1933/1992) “Confusão de língua entre os adultos e a criança”, Psicanálise IV, p.97-106. . (1932/1990) Diário clínico. São Paulo: Martins Fontes.

GREEN, A. (1990) Le tournant des années folles, in La folie privée. Paris: Gallimard.

(2007) Pourquoi les Pulsions de destruction ou de mort? Paris: Éditions Panamá.

GRANOFF, W. (1998) Ferenczi: falso problema ou verdadeiro mal-entendido, in Agora — Revista de Psicanálise, v.I, n.1, jul/dez, p.129-150. 
MELO NETO, J. C. Uma aula do poeta que combatia a "emoção fácil" na poesia, Entrevista junho 10, 2007, retirado de www.geneton.com.br/archives/000210.html.

PACHECO-FERREIRA, F., MELLO, R. e HERZOG, R. Insistências traumáticas e memória corporal: uma leitura ferencziana. Estudos da Língua(gem). Vitória da Conquista v.11, n.1 p.111-128, junho de 2013.

PINHEIRO, T. (1995) Ferenczi: do grito à palavra. Rio de Janeiro: Jorge Zahar/ Editora UFRJ.

VERZTMAN, J.; PACHECO-FERREIRA, F. (2008) O uso do afeto na obra de Sándor Ferenczi. Cadernos de Psicanálise (Círculo Psicanalítico/RJ), v.21, p.45-78.

Fernanda Pacheco-Ferreira

fpachecoferreira@gmail.com

Regina Herzog

rherzog@globo.com 